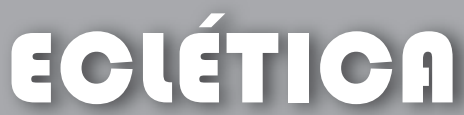 química
}

\section{ESTUDO PRELIMINAR DO VERMICOMPOSTO PRODUZIDO A PARTIR DE LODO DE ESGOTO DOMÉSTICO E SOLO}

\author{
P. R. D. Silva; M. D. Landgraf; T. C. Zozolotto; M. O. O. Rezende (*) \\ Instituto de Química de São Carlos - Universidade de São Paulo - CP - 780. CEP 13566-590 - São Carlos, SP, Brasil \\ I. Pelatti \\ Serviço Autônomo de Água e Esgoto - Av. Getúlio Vargas, 1500. CEP 13570-390 - São Carlos, SP \\ ${ }^{(*)}$ mrezende@iqsc.usp.br
}

\begin{abstract}
Resumo: O lodo de esgoto doméstico é um resíduo gerado durante os processos de tratamento de esgoto, podendo ser estabilizado por diversos processos químicos, físicos e biológicos. O lodo de esgoto estabilizado (biossólido) não possui um destino final adequado e gera diversos problemas no sentido de sua disposição final. Dentre os muitos processos que visam à disposição do biossólido, destaca-se a reciclagem agrícola. A utilização da vermicompostagem como meio de estabilização do lodo de esgoto mostra-se como uma ferramenta útil na estabilização deste resíduo. O processo de vermicompostagem apresentou características físico-químicas satisfatórias para ser utilizado como técnica de estabilização do lodo de esgoto doméstico. O produto final apresentou potencial para ser utilizado na agricultura como fertilizante ou condicionador de solos.
\end{abstract}

Palavras-chave: biossólido, minhocas Eisenia foetida, vermicompostagem, fertilizante

\section{Introdução}

O lodo de esgoto é um resíduo rico em matéria orgânica (MO), gerado durante os processos de tratamento das águas residuárias nas Estações de Tratamento de Esgotos (ETEs) [1,2].

A adição de MO é de fundamental importância para a manutenção do potencial produtivo do solo, por isso a possibilidade do aumento do C orgânico proporcionado pela adição do lodo tem efeito positivo nas propriedades químicas e físicas e, conseqüentemente, na produtividade agrícola. O lodo de esgoto promove o aumento de cargas negativas devido à sua alta concentração de $\mathrm{MO}$, além de enriquecer o meio principalmente com $\mathrm{Ca}^{2+}$ e $\mathrm{Mg}^{2+}$, fato que contribui para o aumento da CTC [3-5].
Com a finalidade de diminuir, ou até mesmo eliminar alguns inconvenientes presentes no lodo de esgoto doméstico, são empregados processos químicos, físicos e biológicos visando a uma estabilização desse material. Após sua estabilização, o lodo original recebe o nome de biossólido [1].

Apesar dessa etapa de estabilização, o biossólido continua gerando vários problemas quanto a sua disposição ou destino final e, na maioria das vezes, acaba causando algum tipo de impacto ambiental [6].

Dentre os muitos processos de disposição final, destaca-se a reciclagem agrícola pela sua adequação sanitária e ambiental [6]. Dependendo do processo químico empregado na estabilização do lodo, o biossólido pode tornar-se alcalino, inviabilizando o seu uso em solos agricultáveis. 
A adição de biossólidos alcalinizados no manejo do solo, pode elevar o $\mathrm{pH}$ a patamares em que a dinâmica de nutrientes e a atividade biológica dos solos são drasticamente alteradas, prejudicando a absorção de nutrientes, o desenvolvimento e a produtividades das culturas [6]

Alguns pesquisadores $(1,2,7)$ observaram que, com elevação do $\mathrm{pH}$ pela adição do lodo $\mathrm{c}$ leado, a produtividade foi reduzida, em razão de o estoque de $\mathrm{N}$ no sistema solo-planta apresentar níveis muito acima do necessário. Portanto, o pH inicial do solo representa um dos fatores que devem ser considerados como limitante de dosagens para o lodo caleado.

Visando a sanar este problema propõe-se a utilização do lodo de esgoto como matriz para a produção de húmus de minhoca ou vermicomposto. Este fertilizante é conhecido por seu alto teor de matéria orgânica estabilizada [8].

A vermicompostagem é o processo de transformação de matéria orgânica recente em matéria orgânica estabilizada, através da ação das minhocas junto com a microflora que vive em seu trato digestivo [8]. No intestino das minhocas, os restos orgânicos que não foram digeridos, bem como os que não foram assimilados, são expelidos juntame com as patículas de terra, na for ju um composto organico rico en nutientes, que de um conposto organico rico en nuice recebe o none de coprólito, send similável pelas plantas $[8,9]$.

A tecnologia da vermicompostagem, que abrange ambas as metas sociais e ambientais de desenvolvimento sustentável, é amplamente utilizada em países, como a Índia, Austrália e Nova Zelândia, Cuba e Itália [10-12]. Essa prática de estabilização pela ação das minhocas pode ser aplicada no tratamento de resíduos orgânicos municipal, industrial e biossólidos [13]. O resulu do processo do processo de vercompostagem é um produto de
alta qualidade que ser utilizado como regulador da alta qualidade que ser utilizado
matéria orgânica do solo $[8,9]$.

Façanha, e colaboradores. avaliaram a bio-
beria orgânica do solo [8,9]. tividade dos ácidos húmicos de lodo de esgoto e de vermicomposto com relação ao transporte de prótons através da membrana plasmática de células de raízes de café e milho [14]. Em ambos os tratamentos houve estimulo da $\mathrm{H}^{+}-\mathrm{ATP}$ ase de membrana plasmática com a presença de grupa- mentos de auxina, indicando a bioatividade dos ácidos húmicos [15].

O presente trabalho tem por objetivo principal a utilização da vermicompostagem como forma de estabilização do lodo de esgoto, uma vez un pode ser incorporado em solos agricos processo ado com condicio solos agricolas e utilipossuir a vantagem de ser um processo de fácil realização e de baixo custo operacional, quando comparado com outros processos sugeridos. Fo utilizado o resíduo gerado pelo tratamento de esgoto, via reator UASB, da estação de Água Vermelha, distrito de São Carlos, SP, gerenciado pelo SAAE - São Carlos.

\section{Material e Métodos}

\section{Preparo do vermicomposto}

Para a realização do experimento foi monada uma caixa de $0,700 \mathrm{~m}$ de comprimento, 0,700 $\mathrm{m}$ de largura e $0,700 \mathrm{~m}$ de altura. A esta caixa foram adicionados solo e lodo de esgoto líquido e na forma pastosa, na proporção de 7:4 (solo: esgoto líquido) mais 8,00 kg de material pastoso e, em seguida, foram inoculadas 400 minhocas da espécie Eisenia foetida.

As determinações da temperatura foram realizadas sempre no mesmo período do dia, às 11:00 horas da manhã no centro das caixas, com auxílio de um termômetro durante todos os 60 dias de vermicompostagem, de acordo com a Instrução Normativa $\mathrm{N}^{\circ} 23$ de 31/08/2005 do Ministério da Agricultura, Pecuária e Abastecimento - MAPA [13]

Após a inoculação das minhocas, o material foi compostado durante 60 dias [9] e o procolizac̃o de coletas de amostras e dete com a de vários pâ̂m de vários parâmetros. A anostra 1 foi coletada imediatamente após a mistura de solo e lodo; amostra 2 foi coletada após 15 dias e assim sucessivamente, de 15 em 15 dias durante os 2 meses de experimento

\section{Metodologia Analítica}

Determinação da Taxa de Umidade e do Teor de Matéria Orgânica

Uma amostra de aproximadamente 10,00 foi pesada em cadinho e levada à estufa, à temperatura de 100 a $110{ }^{\circ} \mathrm{C}$, por 12 horas. Após ess tempo, retirou-se a amostra da estufa, a qual permaneceu em dessecador até alcançar o equilíbrio com a temperatura ambiente, sendo então, pesada. Pela diferença de massas calculou-se a taxa $\mathrm{d}$ umidade. Essa mesma amostra foi levada à mufla por 4 horas, sendo posteriormente pesada para determinação do teor de matéria orgânica.

Determinação do Carbono Orgânico Total (TOC)

Uma massa de 100,00 mg da amostra seca estufa foi introduzida no tubo de combustão de um equipamento Shimadzu modelo TOC- $V_{C p}$ e oxidada cataliticamente à temperatura de $680^{\circ} \mathrm{C}$, sendo os componentes do carbono total convertidos a dióxido de carbono e determinados por espectroscopia de infravermelho.

Determinação do Nitrogênio Kjeldahl Total (NKT)

A uma alíquota de $0,500 \mathrm{~g}$ da amostra adicionaram-se $7,00 \mathrm{~mL}$ de $\mathrm{H}_{2} \mathrm{SO}_{4}$ concentrado aquecendo-se a mistura a $320^{\circ} \mathrm{C}$. Após $15-20$ minutos adicionaram-se gradativamente $7,00 \mathrm{~mL}$ de $\mathrm{H}_{2} \mathrm{O}_{2}$ $30 \%$ A mistura final foi dilúda para 100,00 mL com água destiladae a determinac̃o do nitrogenio com água destilada e a detninação do nitrogênio 399 Nitrogênio Kjeldahl Total (NKT) [16]

\section{Razão C/N}

A razão $\mathrm{C} / \mathrm{N}$ foi determinada dividindo-se razão atômica de carbono total pela razão atômica de nitrogênio total.

Determinação Qualitativa de Ácido Húmico $(A H)$
A extração e purificação de AH foi realizada ajustando-se o procedimento da Sociedade Internacional de Substâncias Húmicas, basead nas extrações ácido-base seguido de purificaç̃o através de sucessivas eluições em resinas de troca iônica [17-19].

Determinação da quantidade de ovos de Helmintos viáveis

O método utilizado foi o de sedimentação, que consiste em ressuspender, inicialmente, sedimento com solução de sulfato de zinco 33\% (densidade 1,18) e solução álcool ácida e posterior sedimentação com solução de ácido sulfúrico $0,1 \mathrm{~mol} \mathrm{~L}^{-1}$. Observa-se o sedimento em câmara de Sedgewick Rafter e se determina a quantidade de ovos viáveis [20].

\section{Resultados e Discussão}

As Tabelas 1 e 2 apresentam a evolução dos parâmetros do material em degradação, nos diferentes estádios do processo de vermicompostagem.

$\mathrm{O}$ teor de umidade manteve-se constante após os primeiros 15 dias de vermicompostagem. À medida que o tempo de vermicompostagem aumentou, houve um decréscimo no teor de matéria orgânica, indicando processos de estabilização, o que levou a um enriquecimento do conteúdo de ácidos húmicos, Tabela 2. Isso ocorre devido à alimentação das minhocas, que utilizam parte da matéria orgânica existente no vermicomposto para seu desenvolvimento, evidenciando que o processo de vermicompostagem está em andamento, evidenciando também a mineralização do carbono orgânico para $\mathrm{CO}_{2}$.

$\mathrm{O}$ aumento da concentração de nitrogênio nos vermicompostos é proporcionado pela redução na massa de material, notadamente carbono, liberado nos processos metabólicos das minhocas. A relação $\mathrm{C} / \mathrm{N}$ indica o grau de incorporação do $\mathrm{N}$ na estrutura de $\mathrm{SH}$ e o grau de humificação. Uma alta relação $\mathrm{C} / \mathrm{N}$ indica baixa incorporação de $\mathrm{N}$ e baixo grau de humificação. A relação 
$\mathrm{C} / \mathrm{N}$ nos $\mathrm{AH}$ e $\mathrm{HF}$ encontram-se dentro da faixa que indica estabilidade biológica $(11,22 \pm 0,21$ - 12,83 $\pm 0,06),[18,19,21,22]$.

Durante todo o processo de vermicompostagem a relação $\mathrm{C} / \mathrm{N}$ diminuiu gradativamente, indicando a capacidade das minhocas em concentrar o nitrogênio. Vale ressaltar que o material inicial, utilizado no processo, era rico em nitrogênio.

A aceleração no processo de humificação promovido pelas minhocas durante a vermicompostagem promove uma diminuição na razão C/N (23).

Os valores encontrados para razão $\mathrm{C} / \mathrm{N}$ ao final do processo estão abaixo dos citados na literatura $(22,23)$ para utilização do húmus de minhoca na agricultura. Porém, estes valores, mesmo estando abaixo dos citados na literatura, não devem interferir no caráter fertilizante do vermicomposto, uma vez que a razão $\mathrm{C} / \mathrm{N}$ indica o grau de humificação do vermicomposto.

Tabela 1. Variação da taxa de umidade (U) e do teor de matéria orgânica (MO) com o tempo.

\begin{tabular}{ccc}
\hline Amostra & $\mathrm{U}(\%)$ & $\mathrm{MO}(\%)$ \\
\hline 1 & $29,54 \% \pm 4,38$ & $11,45 \% \pm 0,90$ \\
2 & $22,22 \% \pm 0,82$ & $8,47 \% \pm 0,63$ \\
3 & $20,82 \% \pm 1,12$ & $7,92 \% \pm 1,30$ \\
4 & $22,91 \% \pm 0,47$ & $8,24 \% \pm 0,31$ \\
5 & $22,70 \% \pm 0,39$ & $8,07 \% \pm 0,25$ \\
\hline
\end{tabular}

Tabela 2. Porcentagem de ácidos húmicos (AH) e relação $\mathrm{C} / \mathrm{N}$ ao longo dos 60 dias de vermicompostagem.

\begin{tabular}{ccc}
\hline Amostra & AH (\%) & C/N \\
\hline $1^{\mathrm{a}}$ & $1,95 \pm 0,01$ & $12,83 \pm 0,06$ \\
$2^{\mathrm{a}}$ & $2,51 \pm 0,01$ & $12,55 \pm 0,14$ \\
$3^{\mathrm{a}}$ & $2,67 \pm 0,01$ & $12,20 \pm 0,26$ \\
$4^{\mathrm{a}}$ & $4,72 \pm 0,01$ & $12,06 \pm 0,40$ \\
$5^{\mathrm{a}}$ & $5,11 \pm 0,01$ & $11,22 \pm 0,21$ \\
\hline
\end{tabular}

O número de ovos de helmintos viáveis sofreu um decréscimo ao longo do experimento, começando com uma quantidade de 4,70 no início e passando para aproximadamente 0,00 ao término do processo de vermicompostagem. A Instrução Normativa No 23 de 31/08/2005 do Ministério da Agricultura, Pecuária e Abastecimento - MAPA [13], estabelece os limites para concentração de ovos viáveis de helmintos em biossólidos. Para a classe A, serão permitidos para o uso na agricultura brasileira a partir de 2011 (CONAMA, 2006); 0

limite máximo de 0,25 ovos viáveis de helmintos por grama de matéria seca, que será padrão brasipor grama de maráríria seca, que será pados de uso agrícola.

Eastman, 2001 [24], demonstrou a viabilidade de se utilizar a vermicompostagem para eliminar ovos de helmintos e outros parasitas, de lodos de esgoto. $\mathrm{O}$ autor sugere que a vermicompostagem é um método relativamente barato que apresenta resultados satisfatórios comparado com outros métodos de estabilização de biossólidos, sugeridos pela United States Environmental
Protection Agency (USEPA) [25]. Além disso, a grande vantagem da vermicompostagem é a eliminação da etapa de precompostagem [21,24].

A vermicompostagem pode ser considerada mais eficiente na higienização de lodos de esgoto que a compostagem Diońsio e Resseti, 1997 (26) a compstion $100 \%$ dos ovos e larvas viaveis [26] Aliminaric de Ascaris lumbricoides, Enterobius vermicula-

Figura 1. Teor de AH em função do tempo de vermicompostagem. ris e ancilostomídeos ao inocularem minhocas da espécie Eisenia fetida em biossólido compostado. Segundo os autores as minhocas possuem melhor desenvolvimento quando criadas em mas contaminas por patógenos humanos, tais como coliforme fecais, protozónios e ous, tas, pois esses patógenos servem de alimento [26-27].

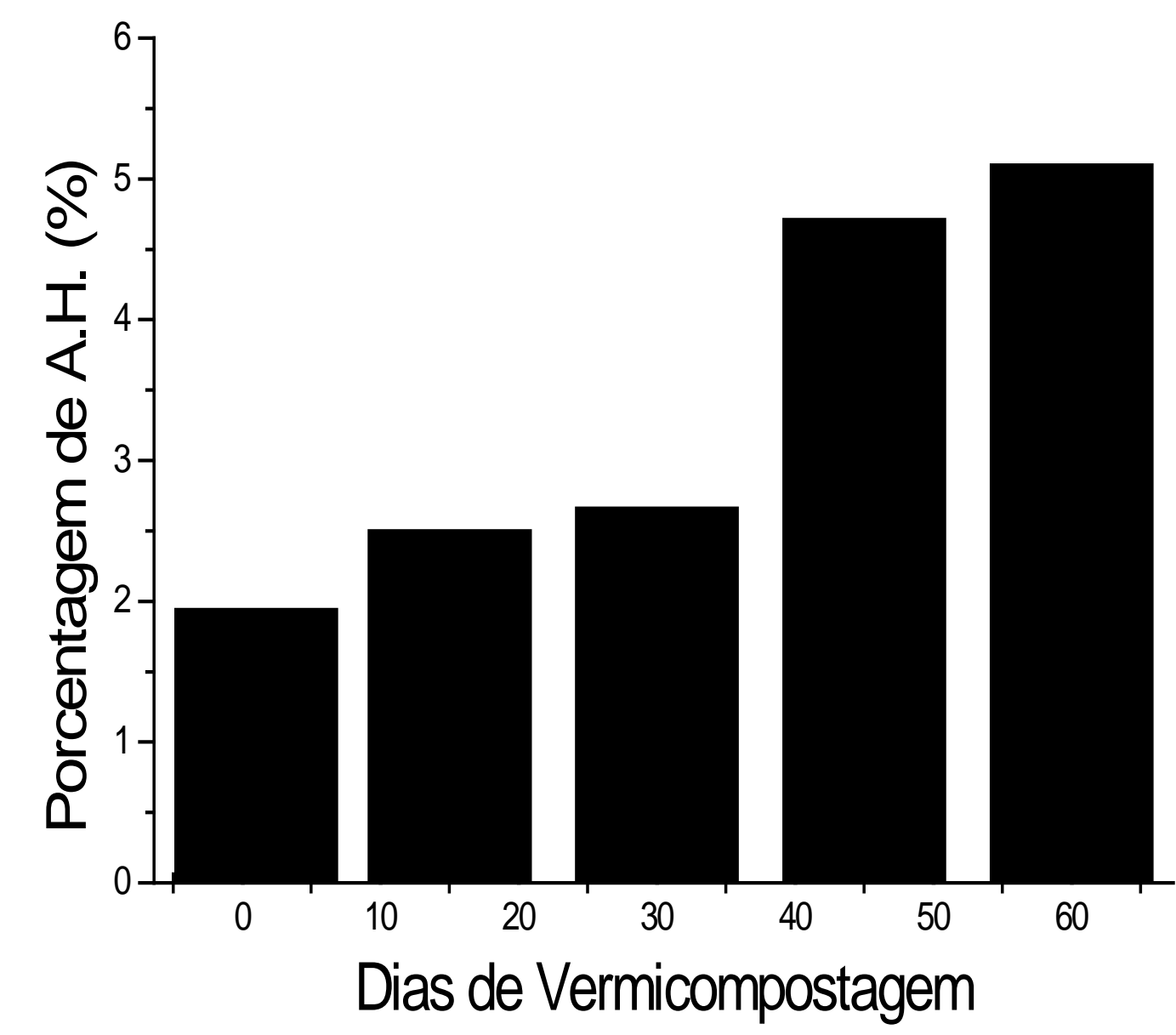




\section{Conclusões}

Pelos estudos realizados fica evidente que a vermicompostagem pode ser uma importante feramenta para reciclagem de lodo com grande diminuição na quantidade de ovos viáveis de helmintos.

A vermicompostagem apresenta estabilização do lodo, produzindo um vermicomposto rico em ácidos húmicos, com uma alta capacidade para reter umidade e com valor da relação $\mathrm{C} / \mathrm{N}$ próxima a sugerida na literatura para processos de humificação

Abstract: Domestic waste, a residue generated during sewage treatments, can be stabilized by many chemical, physical and biological processes. However, the stabilized waste (biosoil) currecycling. The use of vermicomposting has shown to be useful as a mean to stabilize domestic waste. The biosoil achieved through this method exhibits high humidity-retaining capacity, good $\mathrm{C} / \mathrm{N}$ relationship, as well as a satisfactory percentage of humic acid, thus being able to be incorporated into the soil as a conditioner and fertilizer.

\section{Keywords: Biosoil, earthworms Eisenia foetida, vermicomposting, fertilizer}

\section{Referências}

[1] C.V. Andreoli, Resíduos Sólidos no Saneamento Processos de Reciclagem e Disposição Final, 1ª ed., Rio de Janeiro, 2001.

[2] F.R.A. Bidone, J. Povinelli, Conceitos Básicos de Resíduos Sólidos. 1e ed, EESC/USP: São Carlos 1999.

3] W. J. Melo, M. O Marques, G. Santiago Revista Brasileira de Ciência do Solo, 18 (1994), 449.

[4] F. J. Stevenson, Humus chemistry: Genesis, composition, reactions, 2, ed. John Willey, New York, USA. 496pp. 1994. [5] J.E. Silva, D.V. S Resck, R.D. Sharma Alternativa agronômica para o biossólido: A experiência de Braślia. In: Impacto ambiental do uso do lodo de esgoto. Jaguriúna, Embrapa Meio Ambiente, 2000 p. 143-151.

[6] W. Bettiol, O. A. Camargo, Impacto Ambiental do Uso Agrícola do Lodo de Esgoto, Embrapa Meio Ambiente, Jaguariúna, 2000

7] A. Walkowiak, Pol. J. Natur. Sc. 22 (2007) 83

[8] C. A. Edwards, BioCycle. 36 (1995) 56.

9] M. D. Landgraf, M. R. Alves, S. C. Silva, M. O. O. Rezende, Química Nova 22 (1999) 483.

[10] M. Snel, Biocycle. 4 (1999) 75.

11] M. Werner, J. R. Cuevas 6 (1996) 57

12] M. Appelhof, K. Webster, J. Buckerfield, Biocycle 6, (1996) 63.

13] BRASIL. Ministério da Agricultura, Pecuária e Abastecimento. Secretaria de Apoio Rural e Cooperativismo. Instrução normativa $\mathrm{N}^{0} 23$. 31 de agosto de 2005. Brasilia: Ministeŕrio da Agricultura, Pecuária e Abastecimento, 2004, $18 \mathrm{p}$
[14] A. R. Façanha, A. L. O. Façanha, F. L. Olivares, F. Guridi, G. A. Santos, A. C. X. Velloso, V. M. Rumjanek, F. Pesquisa. Agropecuária. Brasileira V. 1.37. No.9 Braślia Sept. 2002.

15] A. R. Façanha, L. De méis, Plant Physiology, Rockville, 108 (1995) 241

16] J. A. O. Cotta, F. H. Salami, A. R. Marques, M. O. O. Rezende, M. D. Landgraf, Revista Analítica, 26 (2007) 68. [17] http://www.ihss.gatech.edu/soilhafa.html, acessada em Janeiro 2008.

18] J. F. Stevenson, Humus chemistry, Genesis, Composition, Reactions, John Wiley \& Sons New York 2a ed., 1994.

[19] M. D. Landgraf, R. A. Messias, M. O. O. Rezende, $A$ Importância Ambiental da Vermicompostagem: Vantagem e Aplicação, Rima, São Carlos 1ํㅗㄹ. ed., 2005.

[20] V. T. Soccol, R. C. Paulino, E. A. Castro Metodologia de análise parasitologica em lodo de esgoto e esgoto. In: manua de métodos para análises microbiológicas e parasitológica em reciclagem de lodo de esgoto (1998), SANEPAR/PROSAB, Paraná, p.27. Bioresource Technology 78 (2001) 11.

[22] M. Kayhanian, G. Tchobanoglous Water Science \& Technology 27 (1993) 133.

[23] E. I. Jiménez, V. P. Garcia. Agriculture Ecosystems and Environment 38, (1992), 331.

24] B.R. Eastman, P. N. Kane, C. A. Edwards, L. Trytek B. Gunadi, A. L. Stermer, J.R. Mobley . Compost Science \& Utilization, 9 (2001), 38. [25] USEPA - United States Environmental Protection
Agency. A guide to the biosolids risk assessments for the
[21] R.M. Atiyeh, C.A. Edwards, S. Subler, J.D. Metzger
EPA Part 503 rule, 1995. Washington: Office of Wastewater Management, EPA/832-B-93-005, 1995. 195

[26] J. L. Dionísio, R. R. Resseti. Revista Técnica da Sanepar,

Curitiba, 8 (1997) 50

[27] R., Srivastava, D., Kumar, S.K Gupta. Bioresource Technology 96 (2005) 1867.

[28] Masciandaro, G., B. Ceccanti, C. Garcia. Soil Biology and Biochemistry, 32 (2000)1015. 